\title{
CAPACIDADE DE AUTODEPURAÇÃO DE UM TRECHO DO RIO CORUMBATAÍ, SP, BRASIL
}

\section{AUTODEPURATION CAPACITY OF A STRETCH OF THE CORUMBATAÍ RIVER, SP, BRAZIL}

\section{Palma-Silva, G.M. ${ }^{1}$; Tauk-Tornisielo, S.M. ${ }^{1}$; Pião, A.C ${ }^{2}$}

${ }^{1}$ Centro de Estudos Ambientais, CEA, Universidade Estadual Paulista, UNESP, Campus de Rio Claro, Avenida 24-A, 1515, Bela Vista, CEP 13.506-900, Rio Claro, SP.E-mail seb@rc.unesp.br

${ }^{2}$ Instituto de Geociências e Ciências Exatas, IGCE, Universidade Estadual Paulista, UNESP, Campus de Rio Claro, Avenida 24-A, 1515, Bela Vista, CEP 13.506-900, Rio Claro, SP. E-mail pião@rc.unesp.br

\section{RESUMO}

O Índice de Depuração do baixo curso do Rio Corumbataí, SP, foi avaliado considerando a importância da água, quanto à qualidade e quantidade para abastecimento público através do índice K2. Sazonalmente nos períodos úmido/quente e seco/frio foram realizadas coletas em dois afluentes do Rio Corumbataí, o Rio Passa-Cinco e o Ribeirão Água Vermelha. As coletas foram realizadas no canal dos afluentes e após a foz de cada um deles junto ao rio Corumbataí, medindo-se a velocidade da água, vazão, profundidade, oxigênio dissolvido (OD), demanda bioquímica de oxigênio (DBO), demanda química do oxigênio (DQO) e nitrogênio total (NT). O curso de água do rio Corumbataí serve como receptor de grande quantidade de cargas orgânicas provenientes de fontes difusas tais como efluentes urbanos, rurais e industriais, lançados sem tratamento prévio, ocorrendo um grau de degradação acentuado. O rio Corumbataí, no trecho estudado, possui uma taxa de depuração alta, sendo no período seco/frio de aproximadamente $70,3 \%$, provavelmente decorrente da declividade acentuada, que possui neste trecho, aos seus meandros e formações rochosas de fundo e pela presença de mata ciliar. Desta maneira, esse trabalho pode contribuir para a tomada de decisões de autoridades dos Municípios e da sociedade civil pertencentes ao Comitê da Bacia Hidrográfica PCJ, visando à preservação do manancial e da água de abastecimento público.

Palavras-chave: Autodepuração. Rio Corumbataí. Impactos ambientais. Declividade. Vazão. Índice de depuração. 


\section{ABSTRACT}

The depuration rate of the low stretch of the Corumbataí River, SP, was evaluated by using the K2 index, considering the importance of the quality and quantity of the water as a vital source of drinking water. Water samples were taken in the humid/hot and dry/cold seasons in the Corumbataí River and two tributaries, the Passa-Cinco River and the Ribeirão Água Vermelha, measuring the speed of the water, discharge, depth, dissolved oxygen (OD), biochemical oxygen demand (BOD), chemical oxygen demand (COD) and total nitrogen (TN). The watercourse of the Corumbataí River receives large amounts of organic loads proceeding from diffuse sewage from domestic and agro-industrial effluents, discharged without previous treatment, causing a high degree of degradation of its water quality. The lower stretch of the Corumbataí still has a high depuration rate, mainly in the dry/cold period, reaching approximately $70.3 \%$. This autodepuration capacity is probably due to the accented declivity in the stretch studied, to its meandering course and base rock formation, and to the presence of riparian forest. In this sense, this study can contribute information to decision making at the municipal and communitty levels in the "Comitê das Bacias Hidrográficas PCJ", as this watershed is an important drinking water source.

Keywords: Self-depuration. Corumbataí river. Environmental impact. Declivity. Outflow. Depuration rate.

\section{INTRODUÇÃO}

Os rios e lagos têm capacidade de recuperação ou autodepuração decorrentes de fatores físicos como: velocidade das águas, vazão, profundidade, quantidade de oxigênio dissolvido e cascalhamento. Essa capacidade pode ser alterada por intervenção humana, através de barramentos, obras de retificação, ou outras ações. A qualidade dos corpos de água, então, é resultante da capacidade de autodepuração e da intervenção humana (SÃO PAULO, 1995). Entre os fatores mencionados, a velocidade da corrente é de importância fundamental influindo no tempo de permanência das partículas, pelo transporte de materiais até seu ponto de deposição ou assimilação biológica e pela presença de espécies vegetais e animais (BRIGANTE et al., 2003). O transporte da água está relacionado com a força gravitacional, sendo o sentido relacionado com a região de maior altitude para a de menor altitude, portanto, o volume de água transportado é maior do que nas nascentes. Os sedimentos também são transportados e a deposição dos mesmos está associada a fatores geológicos e geomorfológicos da bacia de drenagem. Geralmente, é considerado que a carga de sedimentos tende a aumentar à medida que se aproxima da foz, sendo a sedimentação favorecida por relevo de menor declividade (GORDON et al., 1992). 
O fenômeno da autodepuração se desenvolve no sentido de transformar os compostos orgânicos em substâncias inertes e não prejudiciais do ponto de vista ecológico (SPERLING, 1983; BRANCO, 1986). A autodepuração consiste no restabelecimento do equilíbrio no meio aquático, posteriormente às alterações produzidas. A capacidade de autodepuração de um sistema depende diretamente de dois processos operantes: a desoxigenação $\left(\mathrm{K}_{1}\right)$ e reoxigenação ou coeficiente de reaeração $\left(\mathrm{K}_{2}\right)$. O coeficiente de autodepuração é a medida do processo natural de neutralização da matéria poluidora que atinge um curso de água, incluindo diluição, sedimentação e estabilização química. O fenômeno de reoxigenação ou reaeração é o mais sensível, uma vez que, tanto a poluição como a sua estabilização é determinada em termos de oxigênio dissolvido e déficit de saturação, medidos diretamente (BRANCO, 1986).

A bacia do rio Corumbataí, parte da bacia do rio Piracicaba tem grande importância, pois além dos oito municípios que a compõe, fornece água para o município de Araras. Esta bacia hidrográfica concentra problemas de aproveitamento e controle de recursos hídricos, além de conter grande adensamento populacional (PALMA-SILVA; TAUK-TORNISIELO, 2001). As características do rio Corumbataí no alto curso e médio curso permitem seu enquadramento na classe 2 de acordo com a Resolução CONAMA 357 (BRASIL, 2005). Parte do médio curso e o baixo curso, entretanto, vêm apresentando características que, em alguns trechos enquadram este rio na classe 4. Estas condições são decorrentes da falta de tratamento de $100 \%$ do esgoto produzido na cidade de Rio Claro e outros que são lançados clandestinamente dentro do rio. As monoculturas e exploração mineral de argila e calcário contribuem também para piorar as condições da qualidade da água deste trecho do rio, isto é, entre Piracicaba e Rio Claro (PALMA-SILVA; TAUKTORNISIELO, 2001, CONCEIÇÃO; BONOTTO, 2002; PALMA-SILVA, 2006).

A bacia do rio Corumbataí tem grande importância regional quanto ao abastecimento doméstico e industrial de água para os municípios integrantes da mesma, como também para outros pertencentes a bacias vizinhas, por exemplo, o município de Araras. O rio Corumbataí nasce no município de Analândia a aproximadamente $1.040 \mathrm{~m}$ de altitude e, após percorrer aproximadamente $110 \mathrm{~km}$, desemboca no rio Piracicaba, no município de Piracicaba a $460 \mathrm{~m}$ de altitude. Esta declividade apresentada por este rio, motivou o objetivo deste estudo que foi avaliar a capacidade de autodepuração de um trecho compreendido, entre Rio Claro e Piracicaba, além de outros dois trechos localizados um no Ribeirão da Água Vermelha e outro no rio Passa-Cinco, ambos afluentes do Rio Corumbataí. Este trabalho faz parte de um estudo maior envolvendo qualidade das águas do rio Corumbataí e de seus afluentes, modelos matemáticos de gestão ambiental para esta bacia e outros. 


\section{1. Área de Estudo}

A bacia do rio Piracicaba do Estado de São Paulo ocupa $12.400 \mathrm{~km}^{2}$ dos quais aproximadamente $1581 \mathrm{~km}^{2}$, são abrangidos pela bacia do rio Corumbataí (DEPARTAMENTO DE ÁGUAS E ENERGIA ELÉTRICA, 1999). Esta última situa-se na porção centro-oeste do Estado, entre os paralelos $22^{\circ} 55^{\prime}$ e $47^{\circ} 30^{\prime}$ a oeste de Greenwich, abrangendo os municípios de Analândia, Itirapina, Corumbataí, Santa Gertrudes, Ipeúna, Charqueada, Piracicaba e Rio Claro (CONCEIÇÃO; BONOTTO, 2002).

Sua altimetria varia entre $470 \mathrm{~m}$ na desembocadura no rio Piracicaba, no bairro de Santa Terezinha, na cidade de Piracicaba, e $1.058 \mathrm{~m}$ na Serra do Cuscuzeiro, próximo a cidade de Analândia. O desnível total da nascente até a foz do Rio Corumbataí é de 320 m (KOFFLER, 1994). Na Tabela 1 encontram-se as ocorrências das classes de declividade nas cinco sub-bacias que constituem a bacia do rio Corumbataí: Ribeirão Claro, Passa Cinco, Alto Curso, Médio Curso e Baixo Curso. Classe A representa declividade menor que $2 \%$, classe B declividade de 2 a $5 \%$, classe C declividade de 5 a $10 \%$, classe D declividade de 10 a $20 \%$, classe E declividade de 20 a $45 \%$ e classe $\mathrm{F}$ declividade maior ou igual a $45 \%$.

A bacia do rio Corumbataí pertence à Depressão Periférica Paulista, considerada faixa erosiva deprimida entre escarpas mais avançadas da zona de cuestas (PENTEADO, 1976). Esta inserida na Bacia Sedimentar do Paraná, onde estão presentes diversas unidades estratigráficas (INSTITUTO DE PESQUISAS TECNOLÓGICAS DO ESTADO DE SÃO PAULO, 1981). Entre os vários tipos de solos ocorrem nesta bacia hidrográfica, sendo que $65 \%$ da mesma possuem argissolos vermelho-amarelo e latossolos (KOFFLER, 1994).

Tabela 1 - Dimensão em hectares e classes de declividade na bacia do rio Corumbataí.

\begin{tabular}{|c|c|c|c|c|c|c|c|c|}
\hline \multirow{2}{*}{\multicolumn{2}{|c|}{$\begin{array}{c}\text { Classes de } \\
\text { Declividade }\end{array}$}} & \multicolumn{2}{|c|}{ Afluentes } & \multicolumn{3}{|c|}{ Rio Corumbataí } & \multirow{2}{*}{$\begin{array}{c}\text { Total } \\
\text { (ha) }\end{array}$} & \multirow{2}{*}{$\begin{array}{l}\text { \%do } \\
\text { Total }\end{array}$} \\
\hline & & $\begin{array}{c}\text { Ribeirão } \\
\text { Claro }\end{array}$ & Passa Cinco & $\begin{array}{c}\text { Alto } \\
\text { Curso } \\
\end{array}$ & Médio Curso & Baixo Curso & & \\
\hline $\mathrm{A}$ & $(<2 \%)$ & 4.580 & 830 & 1.310 & 3.340 & 350 & 10.410 & 6,1 \\
\hline $\mathrm{B}$ & $(2$ a $5 \%)$ & 5.500 & 7.410 & 4.720 & 5.310 & 6.180 & 29.120 & 17,0 \\
\hline $\mathrm{C}$ & $(5$ a $10 \%)$ & 11.620 & 15.160 & 10.040 & 11.650 & 10.090 & 58.560 & 34,2 \\
\hline $\mathrm{D}$ & $(10$ a $20 \%)$ & 6.310 & 21.250 & 10.740 & 8.030 & 10.380 & 56.710 & 33,2 \\
\hline $\mathrm{E}$ & $(20$ a $45 \%)$ & 310 & 6.420 & 4.980 & 610 & 1.970 & 14.290 & 8,4 \\
\hline $\mathrm{F}$ & $(\geq 45 \%)$ & - & 1.380 & 390 & 20 & 170 & 1.960 & 1,1 \\
\hline & Total & 28.320 & 52.450 & 32.180 & 28.960 & 29.140 & 171.050 & 100,0 \\
\hline
\end{tabular}

Fonte: KOFFLER (1994)

O rio Corumbataí possui como afluentes principais, o rio Passa Cinco na margem direita e o Ribeirão Claro, na margem esquerda. Entre os anos de 1973 a 1999 foi calculada a vazão média geral, $26,45 \mathrm{~m}^{3} / \mathrm{s}$ do rio Corumbataí 
(DEPARTAMENTO DE ÁGUAS E ENERGIA ELÉTRICA, 2002) sendo que os valores máximo e mínimo foram respectivamente 168 e $6 \mathrm{~m}^{3} / \mathrm{s}$. Comparando-se dados de vazão e de precipitação, verifica-se que o regime do rio é diretamente proporcional a esta última (CONCEIÇÃO; BONOTTO, 2002). As condições climáticas da bacia do rio Corumbataí podem ser consideradas do tipo tropical com duas estações definidas - Cwa na classificação de Koeppen, ou seja, w: seca no inverno, a: mês mais quente com temperatura superior a $22^{\circ} \mathrm{C}$, ou tropical alternadamente seco e úmido, controlado por massas tropicais e equatoriais, que predominam em mais de $50 \%$ do ano (MONTEIRO, 1973). Os ventos dominantes provêm dos quadrantes $\mathrm{S}-28 \%$ e SE - 34\% (COTTAS, 1983), as temperaturas médias anuais já situaram entre 18,1 a $20,9^{\circ} \mathrm{C}$ (TROPPMAIR, 1992) e possui um período quente e chuvoso e outro período frio e seco (INÁCIO; SANTOS, 1988).

\section{MATERIAL E MÉTODOS}

Para o estudo da estimativa da autodepuração do rio Corumbataí, foram realizadas análises das águas de um trecho do rio Corumbataí que foi escolhido após estudos preliminares sobre a qualidade das águas deste rio ao longo de todo o seu percurso, desde a nascente até sua foz (PALMA-SILVA; TAUK-TORNISIELO, 2001).

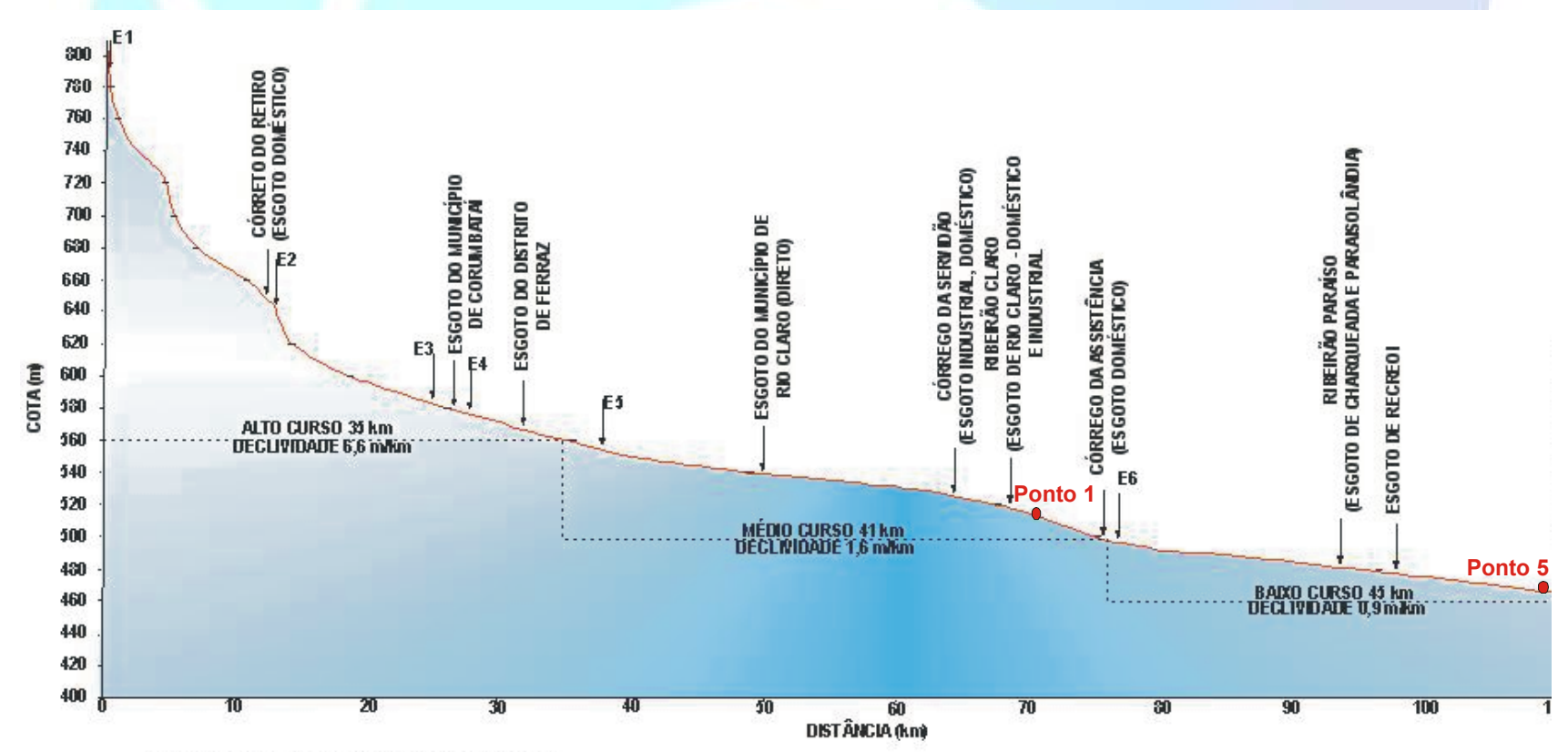

LOCAUZAÇÃO DAS ESTAÇÕES DE GOLETAMO PERFL

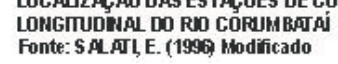

Figura 1. Localização do trecho estudado no Perfil Longitudinal do Rio Corumbataí. 
Foram estabelecidos cinco pontos de coletas de amostras das águas: no distrito de Assistência (Ponto 1); no trecho do rio Passa-Cinco (Ponto 2); no Ribeirão da Água Vermelha (Ponto 3), afluente deste rio; na desembocadura do Ribeirão da Água Vermelha (Ponto 4) e na foz do rio Corumbataí (Ponto 5), após receber as descargas, orgânicas e inorgânicas, no bairro Santa Terezinha do município de Piracicaba (Figura 2).

Foram determinados ainda os parâmetros: demanda bioquímica de oxigênio (DBO); demanda química do oxigênio (DQO); nitrogênio total (NT); fósforo total (PT) e oxigênio dissolvido (OD). As análises dos fatores abióticos foram realizadas no mesmo dia ou no dia seguinte da coleta, com exceção das análises do nitrogênio orgânico total, que foram efetuadas, no máximo, até uma semana após a coleta com as amostras armazenadas a $4^{\circ} \mathrm{C}$. Para fósforo total, foram realizadas duas determinações por ponto de coleta sendo que para a DQO foram utilizadas quatro réplicas para cada ponto de coleta.

O método utilizado para fósforo total $\left(\mu \mathrm{g}^{-1}\right)$ foi descrito por Golterman et al. (1978) e para o nitrogênio orgânico total $\left(\mathrm{mg} . \mathrm{l}^{-1}\right)$ por Mackereth et al. (1978). A DQO (mg. $\mathrm{l}^{-1}$ ) foi verificada através da digestão ácida com dicromato de potássio, aprovada pela USEPA (U.S. Environmental Protection Agency), em reator de digestão marca Hach, modelo COD REACTOR e espectrofotômetro Hach, modelo DR/2000, com precisão de $\pm 1 \mathrm{mg} \mathrm{l}^{-1}$. A demanda bioquímica de oxigênio $\left(\mathrm{DBO}_{5}\right)\left(\mathrm{mgO}_{2} \mathrm{l}^{-1}\right)$ foi determinada nas amostras incubadas durante cinco dias, a $20 \pm 5^{\circ} \mathrm{C}$. O método foi o Iodométrico ou Winkler modificado devido à adição de azida sódica (AMERICAN PUBLIC HEALTH ASSOCIATION, 1998).

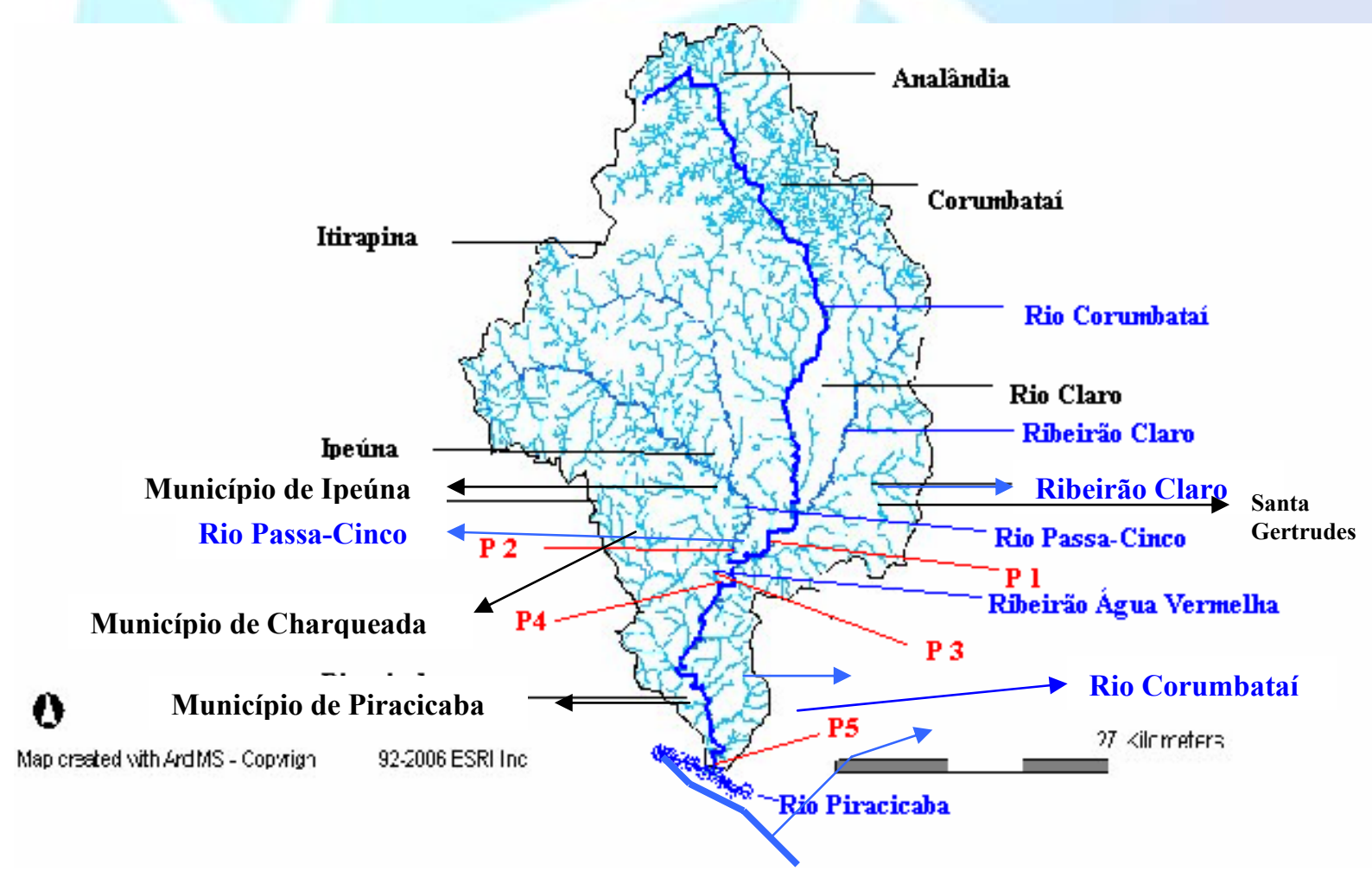

Figura 2. Localização dos pontos de coletas dentro da bacia do rio Corumbataí. 
As vazões foram medidas no mês de setembro (período seco/frio) e janeiro (período chuvoso/quente), sempre no período da manhã entre 7:00 e 12:00 horas. A água foi amostrada a $15 \mathrm{~cm}$ de profundidade da superfície da água e aproximadamente a $50 \mathrm{~cm}$ da margem do rio. Coletas mensais para os demais parâmetros foram realizadas entre julho de 1996 até março de 1998, no período da manhã entre 8:00 e 11:00 horas. As amostras foram acondicionadas em frascos de polietileno de 11 . Para armazenar as águas para as análises de coliformes totais e fecais, foram utilizados frascos de $250 \mathrm{ml}$ previamente esterilizados, devidamente fechados, sendo a tampa envolta com papel protetor (COMPANHIA DE TECNOLOGIA DE SANEAMENTO AMBIENTAL, 1995).

Neste estudo utilizou-se o coeficiente de reaeração, $\mathrm{K}_{2}\left(\mathrm{dia}^{-1}\right)$, com bases logarítmicas, a $20^{\circ} \mathrm{C}$, utilizando-se a fórmula de O’Connor e Dobbins (1958, apud SPERLING, 1983).

$$
K_{2}=1,62 . V^{0,5} / R^{1,5}
$$

Onde:

$\mathrm{V}=$ velocidade média do trecho $\left(\mathrm{m} \mathrm{s}^{-1}\right)$;

$\mathrm{R}=$ profundidade média do trecho $(\mathrm{m})$;

$\mathrm{K}=$ coeficiente de reaeração, base $10,20^{\circ} \mathrm{C}\left(\operatorname{dia}^{-1}\right)$.

$\mathrm{O}$ cálculo de $\mathrm{K}_{2}$ considera os dados hidráulicos, já que as condições de vazão determinam a difusão do oxigênio. Sendo que o $\mathrm{K}_{2}$ aumenta com o acréscimo da velocidade e o decréscimo da profundidade, o que é conceitualmente compreensível, em virtude de se aumentar à turbulência e favorecer condições de pronta renovação da interface, otimizando a reaeração, para isto, dados da vazão destes pontos foram utilizados e calculados a partir da equação de Wisler e Brater (1964) e Lima (1986).

$$
\mathbf{Q}=\Sigma \mathbf{A V E}
$$

Onde:

Q: vazão total da secção em $\mathrm{m}^{3} \mathrm{~s}^{-1}$,

A: área de cada secção em $\mathrm{m}^{2}$,

VE: velocidade de escoamento na subsecção em $\mathrm{m} \mathrm{s}^{-1}$.

\section{RESULTADOS E DISCUSSÃO}

3.1. Carga total da $\mathrm{DBO}_{5}$, DQO, fósforo e nitrogênio totais.

Os resultados obtidos das cargas totais de DBO, DQO, N total e P total estão representados na Tabela 2, correspondendo aos períodos seco/frio e chuvoso/quente. 
Tabela 2 - Carga total dia ${ }^{-1}$ de $\mathrm{DBO}_{5}$, DQO, nitrogênio total, fósforo total, nos pontos de coletas no mês de setembro (seco/frio) e janeiro (chuvoso/quente).

\begin{tabular}{|c|c|c|c|c|c|c|c|c|}
\hline \multirow{2}{*}{$\begin{array}{l}\text { Pontos } \\
\text { de } \\
\text { Coletas }\end{array}$} & \multicolumn{2}{|c|}{ DBO $\left(\mathrm{kg} \mathrm{dia}{ }^{-1}\right)$} & \multicolumn{2}{|c|}{ DQO $\left(\mathrm{kg} \mathrm{dia}^{-1}\right)$} & \multicolumn{2}{|c|}{$\mathrm{N}$ total $\left(\mathrm{kg} \mathrm{dia}^{-1}\right)$} & \multicolumn{2}{|c|}{ P total $\left(\mathrm{g} \mathrm{dia}^{-1}\right)$} \\
\hline & $\begin{array}{l}\mathrm{Seco} / \\
\text { frio }\end{array}$ & $\begin{array}{l}\text { Chuvoso/ } \\
\text { quente }\end{array}$ & $\begin{array}{l}\mathrm{Seco} / \\
\text { frio }\end{array}$ & $\begin{array}{l}\text { Chuvoso } \\
\text { /quente }\end{array}$ & $\begin{array}{l}\text { Seco/ } \\
\text { frio }\end{array}$ & $\begin{array}{l}\text { Chuvoso/ } \\
\text { quente }\end{array}$ & $\begin{array}{l}\text { Seco/ } \\
\text { frio }\end{array}$ & $\begin{array}{l}\text { Chuvoso/ } \\
\text { quente }\end{array}$ \\
\hline 1 & & & & & & & & \\
\hline 2 & 2 & & 5. & & & & & \\
\hline 3 & 4,42 & 49 & 1 & 1 & 5 & 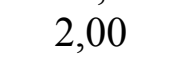 & 0 , & 8 \\
\hline 4 & 125,65 & $12.462,92$ & $21.977,04$ & $50.122,62$ & 300,17 & 541,00 & 124,27 & 280,00 \\
\hline 5 & $2.951,47$ & $15.833,95$ & $23.075,10$ & $40.361,06$ & 375,64 & 620,94 & 130,56 & 258,31 \\
\hline
\end{tabular}

Legenda: 1, Assistência; 2, Passa-Cinco; 3, Ribeirão da Água Vermelha; 4, confluência do Ribeirão da Água Vermelha/rio Corumbataí; 5, foz do Corumbataí.

Comparando os valores da carga total da DBO entre os dois pontos de coletas extremos, 1 e 5, verificou-se um aumento de aproximadamente 1,63 vezes. Os pontos intermediários apresentaram valores menores, como demonstra a Tabela 2.

Este aumento tem ocorrido provavelmente, devido às cargas de esgoto lançadas ao rio, provenientes de colônias de cortadores de cana, sítios, vilarejos, usinas de destilarias, fábricas de aguardentes, olarias, fábricas de produtos químicos e outros existentes neste trecho. A carga remanescente (carga urbana mais a carga industrial) de 1994 do distrito de Recreio, de 9.925,44 kg DBO dia ${ }^{-1}$ (COMPANHIA DE TECNOLOGIA DE SANEAMENTO AMBIENTAL, 1995) foi considerada juntamente com o valor da carga total obtida neste estudo na foz do rio Corumbataí de $2.951,47 \mathrm{~kg}$ DBO dia ${ }^{-1}$. Apesar do aumento verificado até a foz, ainda assim a estimativa da eficiência do poder de autodepuração foi da ordem de $70,31 \%$ para este período seco/frio.

De modo geral, nos pontos de coletas estudados, houve acréscimo da carga total de DBO, em média de 8,32 vezes, no período chuvoso/quente. Neste também foi observado um aumento desta carga na foz do rio Corumbataí, em relação ao Ponto 1. Estes resultados demonstram que apesar da autodepuração do rio, o maior carreamento de material para dentro da cava do rio através das chuvas, vem compensando a grande concentração de materiais orgânicos que ocorre usualmente no período seco/frio, com a diminuição da vazão. Foram constatados os descartes de muitos esgotos clandestinos no trecho estudado do rio Corumbataí.

As cargas totais de DQO, nitrogênio total e fósforo total também aumentaram no ponto de coleta 5 em relação ao Ponto 1 principalmente após os tributários desembocarem no rio Corumbataí (Tabela 2). Provavelmente por ser uma região de plantio de cana-de-açúcar e ter várias fábricas de aguardentes, usinas e atualmente estão sendo aceleradamente instaladas cerâmicas, devem ocorrer contribuições difusas, devido ao deslocamento de resíduos da agricultura e das industrias. 
No período chuvoso/quente os valores das cargas totais de DQO, nitrogênio total e fósforo totais também foram maiores em relação aos valores encontrados no período seco/frio. Quanto a DQO, em média, foi verificado um aumento de seus valores duas vezes mais no período chuvoso/quente. O mesmo ocorrendo para os valores de $\mathrm{N}$ total, 2,6 vezes maior e para o $\mathrm{P}$ total 1,8 vezes maiores. Provavelmente, estes acréscimos decorrentes do carreamento dos incrementos agrícolas utilizados nas culturas de cana-de-açúcar, predominantes, ao longo do trecho do baixo curso do rio Corumbataí. Os valores de DQO demonstram indiretamente a quantidade de matéria orgânica e o potencial redutor presentes nas águas do trecho do rio Corumbataí estudado. Estes valores, contudo, não possibilitam identificar a natureza da matéria orgânica e nem mesmo deferência à constituição química das moléculas oxidáveis. Embora a DQO e a DBO indiquem a demanda potencial de oxigênio dissolvido em água, não há, necessariamente, uma correlação entre elas. Em estudos paralelos foram determinados 21 parâmetros, mensalmente, sobre a qualidade das águas nos pontos de coletas definidos desde a nascente do rio Corumbataí até sua foz, no bairro de Santa Terezinha, desde julho de 1996 a março de 1998. Os resultados encontrados demonstraram uma velocidade acelerada da degradação da qualidade das águas após a área urbana de Rio Claro (PALMA-SILVA; TAUK-TORNISIELO, 2001).

Tanto Salati (1996) como Palma-Silva e Tauk-Tornisielo (2001) encontraram pH ácido na nascente, entre 4,7 e 6,3 e maiores valores mensais entre 5,4 e 7,1, foram encontrados na ETA 2, a montante da área urbana de Rio Claro. Outros estudos, entretanto, demonstraram que o $\mathrm{pH}$ das águas da bacia do rio Corumbataí se encontra próximo da neutralidade (CONCEIÇÃO; BONOTTO, 2002), portanto não confirmando os resultados aqui encontrados e nem mesmos dos valores encontrados pelos primeiros autores.

No trecho do rio Corumbataí aqui estudado, foi constatado que os principais anions e cátions dissolvidos em suas águas estiveram em quantidades situadas dentro dos limites definidos atualmente pela Resolução CONAMA n ${ }^{\circ}$ 357/05 (BRASIL, 2005), excetuando fosfato $\left(\mathrm{PO}_{4}{ }^{3-}\right)$. Estes talvez oriundos dos esgotos domésticos ou das rochas sedimentares da Bacia do Paraná presentes na bacia do rio Corumbataí.

Observou-se uma grande variabilidade espacial e temporal da vazão do Rio Corumbataí. No período seco/frio (inverno), a vazão mínima observada ocorreu no Ponto 4, na confluência Água Vermelha/Corumbataí, em setembro, isto é, no final do período seco. No período úmido/quente, a menor vazão $\left(0,17 \mathrm{~m}^{3} \mathrm{~s}^{-1}\right)$ ocorreu no Ponto 3 (Tabela 3). No período de 1996 a 1998 sempre a vazão mínima foi observada na nascente e a máxima na foz do rio Corumbataí. Durante esse período a época úmida/quente, foi atípica, com pouca quantidade de chuvas e temperaturas mais elevada (PALMA-SILVA; TAUK-TORNISIELO, 2001). A vazão máxima do período chuvoso foi quase o dobro daquela observada na foz do rio Corumbataí, Ponto 5, no período seco, Tabela 3 . Outros autores determinaram a vazão deste mesmo, desde a nascente até a foz, as vazões aumentaram da nascente à foz do Rio Corumbataí, figura 3 (PALMA-SILVA; TAUK-TORNISIELO, 2001) 
O conhecimento da vazão nos locais de coletas é um fator importante e essencial na determinação da autodepuração, pois um sistema fluvial possui mecanismos naturais, por exemplo, a turbulência que regula o transporte de materiais, conferindo certa unidade a todo ecossistema. A velocidade do fluxo de água varia de um ponto a outro e as direções desse fluxo são estreitamente paralelas.

Tabela 3 - Coeficiente de reoxigenação $\left(\mathrm{K}_{2}\right)$ e condições hidráulicas nas estações de coletas no período seco (setembro 1997) e chuvoso (janeiro 1998).

\begin{tabular}{cccc}
\hline $\begin{array}{c}\text { Pontos } \\
\text { de }\end{array}$ & \multicolumn{2}{c}{ Condições Hidráulicas } & Coef. de reoxigenação \\
V (m s s & R (m) & $K 2\left(\operatorname{dia}^{-1}\right)$
\end{tabular}

Coletas Seco/frio Chuvoso/quente Seco/frio Chuvoso/quente Seco/frio Chuvoso/quente

\begin{tabular}{lllllcl}
\hline 1 & 0,40 & 0,55 & 0,51 & 0,91 & 2,81 & 1,44 \\
2 & 0,47 & 0,60 & 0,30 & 0,43 & 2,75 & 4,45 \\
3 & 0,34 & 0,17 & 0,15 & 0,29 & 16,28 & 4,28 \\
4 & 0,25 & 0,44 & 0,98 & 0,54 & 0,84 & 2,70 \\
5 & 0,47 & 0,74 & 0,48 & 0,41 & 4,25 & 5,32
\end{tabular}

Legenda: 1, Assistência; 2, rio Passa-Cinco; 3, Ribeirão da Água Vermelha; 4, confluência do Ribeirão da Água Vermelha com o rio Corumbataí; 5 , foz do rio Corumbataí; V, velocidade média do trecho $\left(\mathrm{m} \mathrm{s}^{-1}\right)$; R, profundidade média do trecho $(\mathrm{m})$.

Entre fevereiro/1998 e janeiro/1999 foi encontrada a vazão média anual para o rio Corumbataí no bairro Santa Terezinha, do município de Piracicaba equivalente a $28,1 \mathrm{~m}^{3} / \mathrm{s}$ (CONCEIÇÃO; BONOTTO, 2002). Os valores para este mesmo ponto, tanto no período seco e no chuvoso (Tabela 3 ), foram inferiores a esta média anual. $\mathrm{O}$ mesmo ocorrendo para os valores da vazão a montante da cidade de Rio Claro em relação a esta média anual acima citada. (Figura 3). 


\begin{tabular}{|l|r|}
\hline Recebido em: $03 / 08 / 2006$ & HOLOS Environment, v.7 n.2, 2007 - P. 149 \\
\hline Liberado para Publicação em: $31 / 10 / 2007$ & ISSN:1519-8634 (ON-LINE) \\
\hline
\end{tabular}

Rio Corumbatai - Vazão

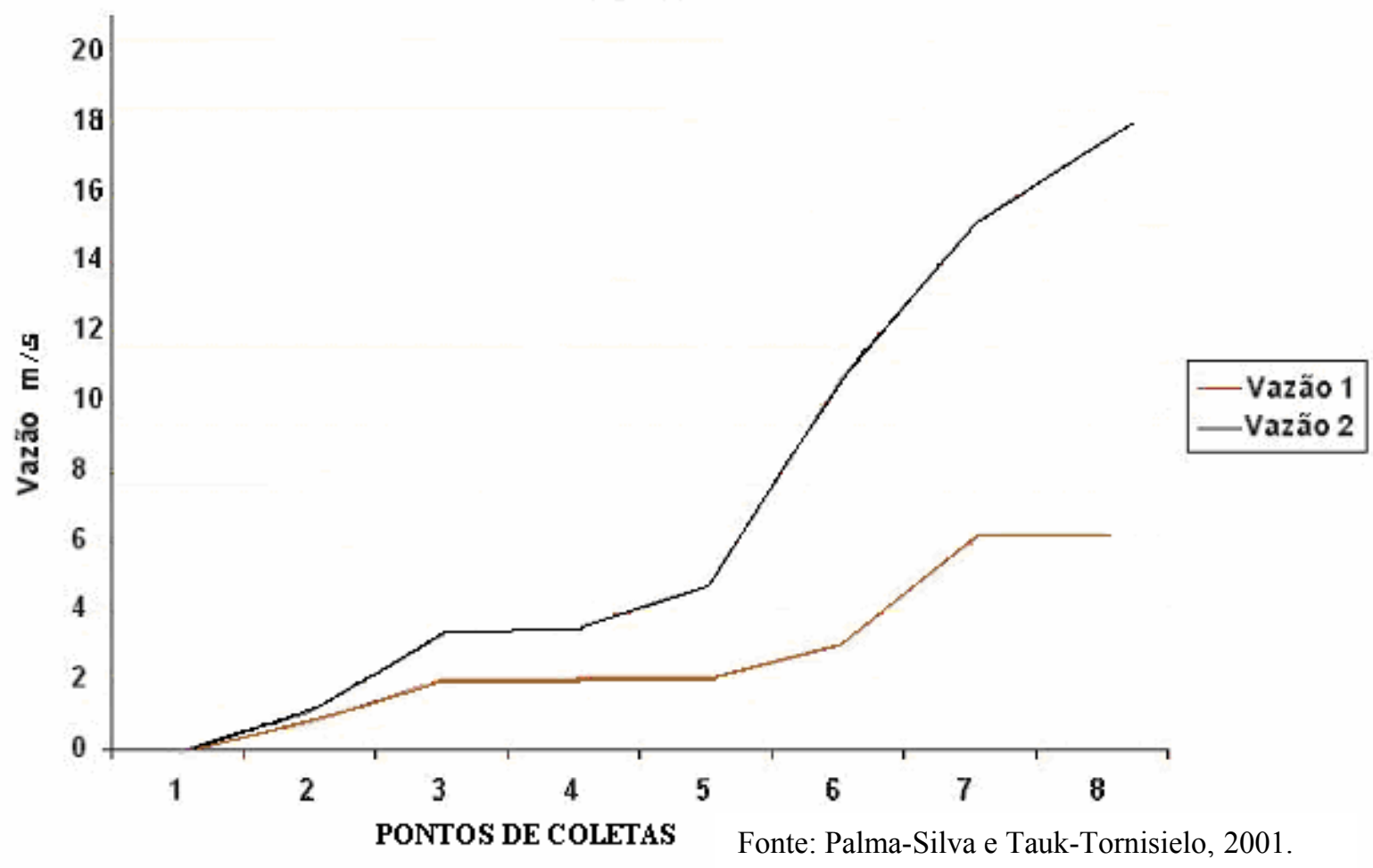

Figura 3. Vazão na calha principal do rio Corumbataí no período seco/frio (vazão 1) e no período chuvoso/quente (Vazão 2). Legenda: 1 - Nascente; 2 - jusante da cidade de Analândia; 3 - montante da cidade de Corumbataí; 4 - jusante da cidade de Corumbataí; 5 - montante da cidade de Rio Claro, ETA 2; 6 - jusante da cidade de Rio Claro; 7 - ETA Capim Fino do SEMAE; e, 8 - na foz do rio Corumbataí.

Para quantificar a evolução da autodepuração foram estabelecidos alguns dos parâmetros, que traduzem o grau de poluição e o estágio da mesma presente no corpo principal do rio Corumbataí. Os valores de $\mathrm{K}_{2}$ para o período de estiagem estão citados na Tabela 3. Estes valores aumentaram com o acréscimo da velocidade e o decréscimo da profundidade, em virtude do aumento da turbulência e por favorecer as condições de pronta renovação da interface, aumentando o valor de reaeração. $\mathrm{O}$ valor mínimo do coeficiente de reaeração ocorreu no ponto de confluência do Ribeirão da Água Vermelha com o rio Corumbataí, no período seco/frio onde este último já recebeu a maioria dos seus principais afluentes. Em sua foz, alguns quilômetros depois, ponto 5, o valor do coeficiente de reaeração deste rio foi de 4,25 $\mathrm{dia}^{-1}$. Os resultados encontrados demonstraram que o rio Corumbataí tem um alto poder de depuração, devido provavelmente a sua declividade (Figura 1). Este rio após a cidade de Rio Claro, especificamente, tem sua reoxigenação maior no período seco em relação ao de chuva, provavelmente devido à grande turbulência que ocorre neste trecho do rio.

Em janeiro (período chuvoso/quente), os menores coeficientes de reaeração foram encontrados no ponto $6\left(1,44 \mathrm{dia}^{-1}\right)$ e no ponto $\mathrm{C}\left(2,70 \mathrm{dia}^{-1}\right)$, verificando-se que não apenas a entrada de esgoto é responsável pelo aporte de matéria orgânica, 
mas também o carreamento intenso de material alóctone introduzido pela chuva. $\mathrm{O}$ maior valor de $\mathrm{K}_{2}\left(5,32 \mathrm{dia}^{-1}\right)$ ocorreu em sua foz, no ponto 8, comprovando o alto poder de autodepuração do rio Corumbataí. Neste ponto, ocorre a maior vazão do rio Corumbataí, conforme demonstrado na figura 3 e resultados encontrados por outros autores (CONCEIÇÃO; BONOTTO, 2002), no ano seguinte a este estudo.

\section{CONSIDERAÇÕES FINAIS}

Os resultados aqui encontrados indicaram que neste período, o carreamento do solo e de outros materiais para dentro do rio vem acarretando maior quantidade de poluentes, apesar do aumento da vazão e conseqüentemente da diluição dos materiais solúveis em água. Em estudos anteriores (PALMA-SILVA; TAUK-TORNISIELO, 2001, CONCEIÇÃO; BONOTTO, 2002) concluíram que no trecho do rio Corumbataí a jusante da área urbana do município de Rio Claro, suas águas apresentam características de Classe 4 devido a diferentes atividades antrópicas e ao adensamento populacional. Os resultados aqui obtidos confirmam estas considerações apesar de que a autodepuração do rio neste mesmo trecho ser alta.

Conclui-se que os impactos causados pelo esgoto doméstico, mineração e agroindústrias contribuem com o enquadramento das águas dentro da Classe 4, apesar do alto poder de depuração do rio Corumbataí.

Apesar das atuações do Comitê de Bacias Piracicaba, Capivari e Jundiaí, de suas Câmaras Técnicas e do Grupo de Trabalho do rio Corumbataí, das fiscalizações da CETESB e DAEE, se não houver um planejamento regional adequado, políticas ambientais regionais com prioridades de ações e estas implantadas efetivamente, haverá nos próximos anos uma degradação do rio acarretando grandes problemas de abastecimento, primeiro para Piracicaba e posteriormente para os demais municípios.

\section{AGRADECIMENTOS}

Este trabalho é parte da dissertação de mestrado da primeira autora defendido no Centro de Estudos Ambientais da UNESP (CEA), sob a orientação da Profa. Dra. Sâmia Maria Tauk-Tornisielo. Agradecemos à FAPESP pela concessão da bolsa de estudo e da reserva técnica.(processo 96/08214-2), ao CEA onde foram realizadas todas as análises laboratoriais da pesquisa, e a todos os funcionários do CEA/UNESP.

\section{REFERÊNCIAS}

AMERICAN PUBLIC HEALTH ASSOCIATION. Standard methods for the examination of water and wastewater. 20 ed. Washington, 1998. 
BRANCO, S. M. Hidrologia aplicada à engenharia sanitária. 3. ed. São Paulo: CETESB, ASCETESB, 1986.

BRASIL. Ministério do Meio Ambiente. Conselho Nacional do Meio Ambiente. Resolução CONAMA 357, de 17 de março de 2005: dispõe sobre a classificação dos corpos de água e diretrizes ambientais para o seu enquadramento, bem como estabelece as condições e padrões de lançamento de efluentes, e dá outras providências. Brasília, DF, 2005. Disponível em: http://www.mma.gov.br/port/conama/res/res05/res35705.pdf Acesso em: 31 jan. 2007.

BRIGANTE, J.; ESPÍNDOLA, E. L. G.; POVINELli, J.; NOGUEIRA, A. M. Caracterização física, química e biológica da água do rio Mogi-Guaçu. In: BRIGANTE, J.; ESPÍNDOLA, E.L.G (Ed.). Limnologia fluvial: um estudo do rio Mogi-Guaçu. São Carlos: RiMa, 2003. p.55-76.

COMPANHIA DE TECNOLOGIA DE SANEAMENTO AMBIENTAL. Avaliação da qualidade das águas. São Paulo, 1995.

CONCEIÇÃO, F. T.; BONOTTO, D. M. Relações hidroquímicas aplicadas na avaliação da qualidade da água e diagnóstico ambiental na bacia do rio Corumbataí (SP). Geochimica Brasiliensis, Rio de Janeiro, v. 16, n. 1, p. 1-21, 2002.

COTTAS, L. R. Estudos geológico-geotécnicos aplicados ao planejamento urbano de Rio Claro, SP. 1983. 2 v. Tese (Doutorado em Geociências) - Instituto de Geociências, Universidade de São Paulo, São Paulo.

DEPARTAMENTO DE ÁGUAS E ENERGIA ELÉTRICA. Ofício BMT/049/99. 1999. (Autos nº 9800084 - DAEE).

DEPARTAMENTO DE ÁGUAS E ENERGIA ELÉTRICA. Secretaria de Obras e do Meio Ambiente. Legislação de recursos hídricos: política estadual. São Paulo, 2002.

GOlTERMAN, H. L., Climo, R. S., OHNSTAD, M. A. M. Methods for physical and chemical analysis of freshwater. $2^{\text {nd }}$ ed. Oxford: Blackwell, 1978. (IBP Handbook, n. 8).

GORDON, N. D.; McMAHON, T. A.; FINLAYSON, B. L. Stream hidrology: an introduction for ecologists. Chichester: John Wiley, 1992. 
INÁCIO, A; SANTOS, M. J. Z. Características climáticas de Rio Claro. Boletim Geografia Teorética, Rio Claro, v. 18, n. 35/36, p. 87-104, 1988.

INSTITUTO DE PESQUISAS TECNOLÓGICAS DO ESTADO DE SÃO PAULO. Inventário cartográfico do estado de São Paulo. São Paulo: IPT, PRÓ-MINÉRIO, 1981.

KOFFLER, N. F. Carta de declividade da bacia do rio Corumbataí para análise digital s16. Geografia, Rio Claro, v. 19, n. 2, p. 167-082, 1994.

LIMA, W. P. Princípios de hidrologia florestal para manejo de bacias hidrográficas. Piracicaba: ESALQ, Departamento de Silvicultura, 1986.

MACKERETH, F. J. H.; HERON, J.; TALLING, J. F. Water analysis: some revised methods for limnologists. Cumbria: Freswater Biological Association, 1978. (Scientific Publication, n. 36)

MONTEIRO, C. A. F. M. A dinâmica climática e as chuvas no estado de São Paulo. São Paulo: IG, USP, 1973.

PALMA-SILVA, G. M. Relação dos indicadores microbiológicos com outros parâmetros limnológicos no rio Corumbataí, no intuito de propor rum modelo matemático para gestão ambiental. 2006. 174 f. Tese (Doutorado em Microbiologia Aplicada) - Instituto de Biociências, Universidade Estadual Paulista, Rio Claro, 2006.

PALMA-SILVA, G. M.; TAUK-TORNISIELO, S. M. Contribuición de las áreas urbanas en la polución del rio de Corumbataí, SP, Brazil. In: CUBA. Ministerio de Ciencias Tecnología y Medio Ambiente. Instituto Superior de Ciencias y Tecnología Nucleares. Contribución a la educación y la proteccion ambiental. Ciudad de la Habana; Editorial Academia; 1999. v. 2, VII Taller, p. 1-11, 2001.

PENTEADO, M. M. Geomorfologia do setor centro ocidental da depressão periférica paulista. São Paulo: IG, USP, 1976. (Teses e Monografias, 22)

SALATI, E. Diagnóstico ambiental sintético e qualidade da água como subsídio para o planejamento integrado da bacia hidrográfica do rio Corumbataí, SP. 1996. 199 f. Tese (Doutorado) - Escola de Engenharia de São Carlos, Universidade de São Paulo, São Carlos.

SÃO PAULO (estado). SECRETARIA DO MEIO AMBIENTE. Recursos hídricos: histórico, gestão e planejamento. São Paulo, 1995. 
SPERLING, V. M. Autodepuração dos cursos d'água. 1983. 366 f. Dissertação (Mestrado em Engenharia Sanitária) - Universidade Federal de Minas Gerais, Belo Horizonte.

TROPPMAIR, H. Atlas da qualidade ambiental e de vida de Rio Claro, SP. Rio Claro: Instituto de Geociências e Ciências Exatas, UNESP, 1992.

WISLER, C. O., BRATER, E. F. Hidrologia. Rio de Janeiro: SEDEGRA, 1964. 